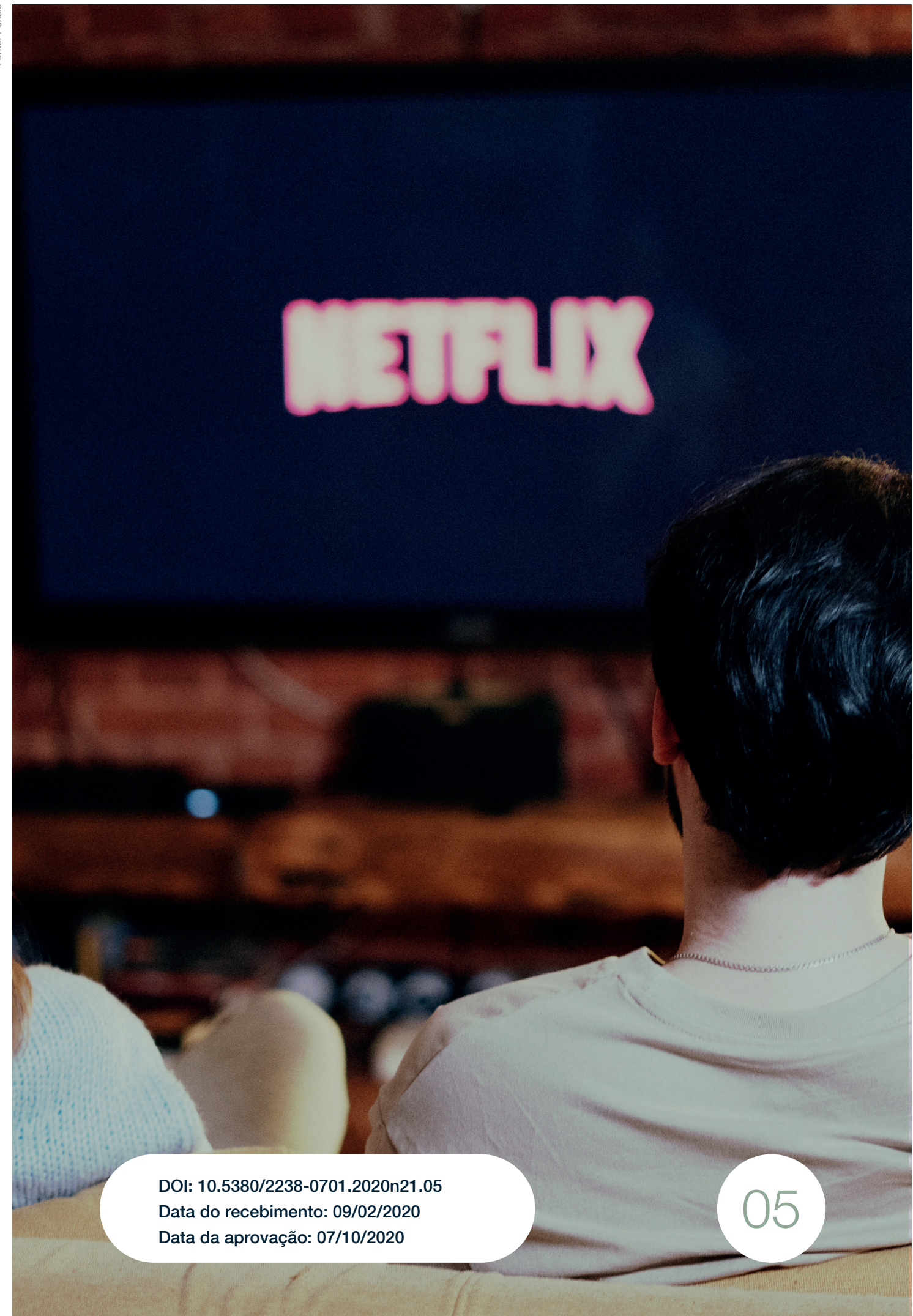


O fluxo midiático dos animês e seus modelos de distribuição e consumo no Brasil 


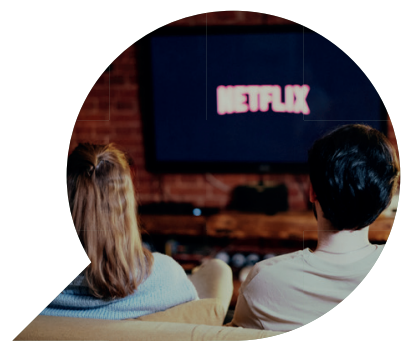

\section{O fluxo midiático dos animês e seus modelos de distribuição e consumo no Brasil}

\section{Anime's media flow and the distribution and con- sumption's models in Brazil}

El flujo mediático del anime y sus modelos de distribución y consumo en Brasil

KRYSTAL URBANO ${ }^{1}$

MAYARA ARAUJO ${ }^{2}$

Resumo: A emergência de serviços licenciados de streaming como a Netflix e o Crunchyroll - contribuíram para a diversificação nas formas de distribuição e consumo dos animês no Brasil. Esse movimento acarreta profundas transformações no ecossistema midiático desse produto cultural. Partindo desse contexto, analisamos as possibilidades que surgem em virtude da popularização dessas plataformas e seu diálogo com os modos tradicionais de distribuição já consolidados no país. Fundamentalmente, defendemos que o novo modelo de fruição de animês atualmente em voga, representado pela emergência e popularização de serviços licenciados de streaming, coexiste e dialoga intimamente com mo-

1 Doutora e Mestre em Comunicação pela Universidade Federal Fluminense (PPGCOM | UFF). Jornalista e Especialista em Epistemologias do Sul (CLACSO | Argentina). Coordenadora Adjunta do MidiÁsia (Grupo de Pesquisa em Mídia e Cultura Asiática Contemporânea - PPGCOM | UFF). 
dos tradicionais (formais e informais) de distribuição e consumo consolidados pela mídia televisiva local e pelos fãs brasileiros nos ambientes digitais.

Palavras-chave: Televisão; Animês; Distribuição; Consumo; Streaming.

Abstract: The emergence of licensed streaming services - such as Netflix and Crunchyroll - contributed to the diversification in the forms of distribution and consumption of anime in Brazil. This movement brings about profound changes in the media ecosystem of this cultural product. With this context, we analyze possibilities that arise due these platform's popularization and its dialogue with traditional modes of distribution consolidated in Brazil. Fundamentally, we argue that the new anime fruition model currently in vogue, represented by the emergence and popularization of licensed streaming services, coexists and dialogues with traditional modes (formal and informal) of distribution and consumption consolidated by local television media and fans Brazilians in digital environments.

Keywords: Television; Anime; Distribution; Consumption; Streaming.

Resumen: La aparición de servicios de transmisión con licencia, como Netflix y Crunchyroll, contribuyó a la diversificación en las formas de distribución y consumo de anime en Brasil. Este movimiento produce cambios profundos en el ecosistema mediático de este producto cultural. Desde este contexto, analizamos las posibilidades que surgen debido a la popularización de estas plataformas y su diálogo con los modos tradicionales de distribución ya consolidados en el país. Fundamentalmente, sostenemos que el nuevo modelo de fructificación del anime actualmente en boga, representado por el surgimiento y popularización de los servicios de streaming con licencia, coexiste y dialoga estrechamente con los modos tradicionales (formales e informales) de distribución y consumo consolidados por los medios de televisión locales y los fans brasileños en entornos digitales.

Palabras-clave: Televisión; Anime; Distribución; Consumo; Streaming 


\section{Introdução}

Criado em 1984, como personagem de quadrinhos pelo autor japonês Akira Toriyama, o menino de cabelos espetados, com rabo de macaco e força sobre-humana, de nome Son Goku, tornou-se parte importante do imaginário produzido pela cultura televisiva japonesa no Ocidente. Desde então, a franquia japonesa Dragon Ball (Doragon Boru), de propriedade da produtora de animação japonesa Toei Animation, contabilizou diversas séries animadas, dezenas de filmes de animação e especiais para TV, nos quais são exploradas diversas fases da saga de Son Goku e de seus amigos em sua jornada à procura das lendárias sete esferas do dragão. A experiência midiática com Dragon Ball teve suas origens nos quadrinhos há mais de 30 anos, mas se tornou bastante popular nos países ocidentais através dos desenhos animados japoneses - os animês ${ }^{3}$-, formato televisivo que colaborou para que a cultura pop japonesa e seus outros produtos relacionados tivessem popularidade para além-mar. De fato, Dragon Ball se constitui atualmente uma vasta experiência transmidiática na qual se misturam inúmeros videogames, sites, blogs, filmes, brinquedos, artigos escolares, curtas-metragens, como muitos outros produtos feitos tanto pela holding que detém a franquia, a Toei Animation, quanto pelos fãs transnacionais que manipulam as tecnologias para dar vida a histórias e roteiros - em fanfics e fan fil$m s^{4}$ - sobre o famoso guerreiro sayajin. Apesar de cada uma dessas expressões oferecer uma experiência singular, é interessante perceber que as séries animadas dessa franquia permanecem como a principal referência no imaginário das audiências globais da referida produção.

Com efeito, o fenômeno Dragon Ball ilustra de maneira contundente o resultado do movimento das indústrias culturais japonesas, iniciado nos anos 1980, a partir da difusão dos produtos da sua cultura pop nos mercados vizinhos e internacionais, uma vez que o arquipélago passou a se apresentar como um forte exportador de produtos de entretenimento para o mundo, abandonando a imagem de um país conhecido por

\footnotetext{
3 No contexto aqui adotado, os animês consistem nos desenhos animados japoneses, em sua versão serializada para TV, tal como conhecemos no Brasil.

4 Fanfics e Fanfilms são produtos midiáticos produzidos por fãs de um dado produto cultural. No primeiro caso, trata-se de produção de ficções e poemas baseados em animês e seus personagens geralmente disponibilizados na internet. Já no segundo caso, trata-se da produção de filmes amadores, no qual os personagens e/ou animês são utilizados com base do enredo e narrativa.
} 
suas indústrias manufatureiras (IWABUCHI, 2002, 2004; SATO, 2007). Sem dúvida, foram os animês (juntamente com os mangás) que capitanearam tais esforços da indústria cultural japonesa, ao desfrutarem de um lugar de destaque no que tange a esfera da diversificação da distribuição de conteúdo audiovisual no cenário global. Especialmente, a difusão internacional dos animês e de suas convenções de gênero5 correlacionadas representou um importante contraponto em relação à lógica de concepção dos desenhos animados estadunidenses (HOLZBACH, 2018), bem como da noção amplamente difundida no ocidente de que essas produções seriam sinônimo de conteúdo infantil. Dessa forma, os desenhos animados japoneses passaram a se configurar como uma opção alternativa ao referido modelo hegemônico (MITTEL, 2003), representado pela indústria estadunidense de animação, sobretudo, junto aos públicos brasileiros. Naturalmente, há certas razões que contribuíram para que os animês pudessem aportar no Brasil como um produto audiovisual com elevado potencial de consumo.

Em primeiro lugar, diferentemente do que ocorreu nos Estados Unidos, onde os animês só encontraram espaço nas grades televisivas nos anos de 1980 (HOLZBACH, 2018), o Brasil veiculava parte desse material já na década de 1960. Os fluxos migratórios de japoneses para o país no início do século XX decerto colaboraram para um contato mais intensivo e precoce com produtos midiáticos oriundos do Japão (MACHADO, 2011). Não obstante, a partir da presença contínua dos animês nas grades da televisão aberta brasileira entre 1960 e 1980, a cultura pop japonesa tornou-se um fenômeno de vulto no país na década de 1990, acarretando o boom dos desenhos animados japoneses nesse mesmo período (NAGADO, 2007). Em segundo lugar, o interesse dos públicos brasileiros em relação a este produto se tornou tão grande entre 1990 e 2000 que a oferta disponível não foi capaz de satisfazê-los, levando o público interessado neste tipo de material a recorrer a outros meios para ter acesso a ele. Em especial, o advento da internet e das

\footnotetext{
5 Em linhas gerais, os critérios empregados no Japão combinam três aspectos fundamentais na composição dos gêneros: 1) o sexo (masculino ou feminino); 2) a faixa etária; 3) a temática central da narrativa (terror, comédia, ficção, fantasia, horror, dentre outros). Assim como há produções direcionadas aos jovens do sexo masculino, ou seja, do gênero shounen, também há produções destinadas ao público adolescente feminino, com as produções do gênero shoujo. Outros gêneros, tais como o josei (temática voltada para a mulher adulta), yaoi (temática homossexual masculina) e o kodomo (temática para o público infantil) e o hentai (o que seria equivalente ao pornográfico), dentre muitos outros gêneros e subgêneros, permite a indústria atender aos mais variados tipos de públicos.
} 
dinâmicas de troca de arquivos a ela associados criou as condições de possibilidades para a emergência de grupos de fãs especializados, que tomaram a iniciativa de traduzir, legendar e distribuir esses produtos midiáticos de maneira voluntária e informal, sem fins lucrativos, no ambiente digital (URBANO, 2013; SIGILIANO; BORGES, 2019). Por fim, o surgimento de serviços licenciados de streaming de filmes e séries no último decênio em nosso país (como o Crunchyroll e a Netflix), vem promovendo significativamente uma maior expansão do conteúdo televisivo japonês, o que vem diversificando os modos de distribuição e consumo dos animês no Brasil.

Partindo de uma perspectiva desocidentalizante no que tange à investigação dos fluxos da cultura televisiva que se verificam em âmbito global (CURRAN; PARK, 2000; THUSSU, 2007; WANG, 2011), o artigo tem como objetivo explorar os antigos e novos modelos de distribuição e consumo dos desenhos animados japoneses no contexto brasileiro. Fundamentalmente, defendemos que o novo modelo de fruição de animês atualmente em voga, representado pela emergência e popularização de serviços licenciados de streaming de filmes e séries de TV, coexiste e dialoga intimamente com modos tradicionais (formais e informais) de distribuição e consumo consolidados pelos movimentos pontuais da mídia televisiva local e dos fãs brasileiros nos ambientes digitais. Devido a isso, o argumento do texto foi dividido em três seções. Na primeira, discutimos o advento dos animês e sua presença na televisão brasileira (aberta e a cabo), a partir de uma perspectiva sócio-histórica, de modo a ilustrar o surgimento de um modelo tradicional e oficial de distribuição e consumo dessas produções em nosso país. Já num segundo momento, apresentamos o modelo intermediário e informal de distribuição e consumo dos desenhos animados japoneses que emergiu na virada do milênio, tendo ancoragem no movimento dos fãs e suas práticas midiáticas no ambiente das redes digitais. Por fim, na seção que encerra o artigo, refletimos acerca dos avanços ocorridos recentemente nos modos de distribuição e consumo dos animês no ambiente digital, a partir das implicações resultantes da popularização das plataformas licenciadas de streaming de filmes e séries de TV no Brasil. 


\section{O advento dos animês na televisão brasileira}

Ao contrário de muitos outros países, o Brasil tem um longo contato com a cultura japonesa. Desde a chegada dos primeiros imigrantes japoneses no país, em 1908, no estado de São Paulo (contratados para trabalhar nas lavouras cafeeiras), à disseminação dos produtos audiovisuais nipônicos na televisão, geralmente desenhos animados japoneses, iniciada na década de 1960, foi um longo caminho percorrido, no que concerne à relação estabelecida, em vários níveis, entre Japão-Brasil. De acordo com Alexandre Nagado (2007):

O animê funciona como um embaixador cultural, levando um pouco da cultura japonesa através das aventuras de personagens coloridos e carismáticos. A invasão iniciada nos anos 60 foi em escala mundial, pois os animês são famosos em toda a Ásia, na Europa, Estados Unidos e América Latina. Do lado de cá do globo, um dos países que mais recebeu títulos de animês foi sem dúvidas o Brasil, que assiste à animação japonesa desde o final dos anos 60 (NAGADO, 2007, p. 72).

No Brasil, a cultura pop japonesa vai se tornar conhecida do público sobretudo a partir da mídia televisiva. Através das séries nipônicas presentes no país desde a década de 1960, os elementos da cultura japonesa se tornaram conhecidos em terras tupiniquins (URBANO, 2013). A primeira série japonesa exibida no Brasil foi Nashônaru Kiddo ou National Kid. Televisionado pela TV Record em meados da década de 1960, esse seriado live-action teve um tímido impacto junto ao público jovem da época, pois o alto custo dos aparelhos televisivos no Brasil impediu sua maior difusão devido a tais limitações. Sobretudo, National Kid é considerado um "clássico" para os fãs do gênero tokusatsu". Foi esta série que preparou o caminho para que outros super-heróis como Ultraman, Ultra Seven e Espectreman desembarcassem nas telas das TVs brasileiras anos depois.

De acordo com Sandra Monte (2010), em 1968 o primeiro animê foi exibido na TV brasileira, na então recém-inaugurada Rede Globo. Trata-

6 Nos primeiros dez anos da TV no Brasil, o aparelho televisor ainda era um artigo de luxo. Segundo Mattos (2002), essa realidade só se altera a partir de 1968, quando o governo lança uma linha de crédito com a qual se podia adquirir um televisor e parcelá-lo em até 36 meses.

7 Segundo Nagado (2007, p. 10), tokusatsu é a abreviatura de "tokushuu kouka satsuei", sendo que "tokushuu kouka" significa "efeitos especiais" e "satsuei" significa "filmagem". O termo passou a designar os filmes e seriados live action associados a grandes monstros de borracha e heróis uniformizados". 
va-se de O Oitavo Homem, considerado o primeiro super-herói cyborg do Japão. No mesmo ano, Capitão Meteoro (título pelo qual Speed Racer foi chamado, primeiramente, no Brasil) foi exibido pela mesma emissora, abrindo espaço para outros títulos como Super Dínamo (Paa Man), A Princesa e o Cavaleiro, Fantomas, Kimba - O leão branco, Sawamu, dentre outros, pudessem ser veiculados em emissoras como TV Tupi e a Rede Record nesse período que compreende o final dos anos 1960 e início da década de 1970. Importante destacar que esses primeiros títulos (live-actions e animês) eram em preto e branco (como National Kid, Super Dínamo, Oitavo Homem) e, a partir da introdução da TV em cores (que ocorre em 1972), nunca mais foram reexibidos na TV brasileira. Não obstante, a censura promovida pelo governo militar junto aos meios de comunicação de massa no país na década de 1970 prejudicou a veiculação das séries japonesas, já que vários itens foram proibidos por serem considerados subversivos, incluindo produções internacionais voltadas ao entretenimento (MATTOS, 2002, p. 103). Decerto, "na década de 70, ninguém poderia prever que os seriados com super-heróis japoneses, robôs gigantes e monstros devastadores fossem fazer tanto sucesso no Brasil, como aconteceria nos anos 80" (PEREIRA, 2008, p. 112).

Portanto, compreende-se que mesmo com a presença dos animês na programação das emissoras brasileiras desde a década de 1960, há que se considerar que produções circulavam em pouca variedade, por serem produtos considerados bastante específicos e direcionados, a princípio, para consumo da comunidade nikkei no Brasil (MACHADO, 2011). Talvez, mais importante neste período que compreende 19601980, é que se tratava de produções que se inseriam na categoria de "enlatados" e, portanto, foram importadas para tapar buracos na programação local, sendo produtos considerados de baixo potencial para o mercado televisivo brasileiro. É só com a chegada da Rede Manchete em $1983^{8}$ que o processo de infiltração dos animês intensifica-se. Essa emissora, em particular, nos parece ter carregado uma vocação para esse tipo de conteúdo, como defende Nagado (2007): "se houve um canal de TV brasileiro identificado com heróis japoneses, foi sem dúvida a extinta TV Manchete, que alavancou manias nacionais puxadas por Jaspion e Cavaleiros do Zodíaco na década de 1990" (NAGADO, 2007, p. 88). Contrariando certas expectativas, as séries animadas japonesas encontram nesta emissora um local legítimo de ancoragem:

8 Para mais informações, ver Mattos (2002). 
Tudo indicava que os anos 80 seriam uma década em que apenas alguns desenhos animados produzidos no Japão, como Patrulha Estelar, estariam representando o Império do Sol Nascente na programação brasileira. Mas a Rede Manchete veio mostrar que havia espaço não somente para os super-heróis de lá, mas também para a criação de um novo segmento de consumidores e fãs. Tudo começou com Jaspion e Changeman. Depois deles, os heróis japoneses criariam uma legião gigantesca de fãs no Brasil, algo nunca imaginado na época de Ultraman e Nacional Kid (PEREIRA, 2008, p. 141).

Na década de 1990 acontece o grande boom dos animês no Brasil. Nesse período, uma vasta quantidade de animês passa a circular na televisão. A expectativa de uma parcela da audiência brasileira era quanto a uma maior circulação e variedade de títulos presentes na grade das emissoras televisivas. Nesse período, marcado pelo licenciamento de alguns títulos de relevo para a TV aberta brasileira, que logo se tornaram manias nacionais (como Cavaleiros do Zodíaco, Sailor Moon, Dragon Ball, Yu Yu Hakusho e Samurai X), também ocorre a consolidação da TV paga no Brasil, dando margens às perspectivas de uma maior circulação dos desenhos animados japonesas, principalmente, por haver uma avidez crescente por esse tipo de programação. Acreditava-se, portanto, que o advento da TV por assinatura como um novo espaço de distribuição para as narrativas seriadas vindas "de fora" solucionaria o "dilema dos fãs de séries internacionais, já que, a partir da segunda metade da década, vários canais começaram a exibir uma variedade soberba de seriados, e muitos se transformaram em objeto de culto" (PEREIRA, 2008, p. 192).

Se, num primeiro momento, a consolidação da TV paga no Brasil parecia resolver um dilema da variedade de oferta dessas produções, num segundo momento, os modos de tratamento concedido aos animês pelas emissoras pagas (como o Cartoon Network, por exemplo) no decorrer do processo de mediação se mostraram semelhantes àqueles aplicados pela TV aberta. Os frequentes cortes e edições de episódios, a ausência de uma cronologia na exibição dos mesmos, mudanças de horário na exibição das séries (sem aviso prévio para os assinantes) são traços que, historicamente, marcam um tipo de tratamento arraigado concedido pelas emissoras abertas e a cabo aos desenhos animados japoneses (URBANO, 2013). 
De fato, o modelo de veiculação e disponibilização dos animês que fora adotado pela TV brasileira - aberta e a cabo - apresenta algumas particularidades que interferem e prejudicam um acompanhamento linear e mais fidedigno destas séries. A crescente demanda que excede a oferta dos animês aqui no Brasil, somados aos constantes cortes e edição de episódios, falta de cronologia na exibição das séries, mudanças de horário e o apagamento do áudio, em japonês, em favor da dublagem das falas dos personagens, em português, dentre outras ações, parece ter impulsionado a migração da audiência televisiva desse produto para internet, local onde é possível consumir e, até mesmo, se envolver ativamente nos processos de produção (informal) de legendas e distribuição de animês, baseado numa lógica de "fã para fã". Assim, frente às opções oficiais que se mostram ineficientes para esses fãs, emerge um modelo intermediário (e informal) de distribuição e consumo de animês no ambiente digital.

\section{A presença e distribuição informal dos animês na internet brasileira}

Os contornos que caracterizam o modelo tradicional de distribuição e consumo dos animês na TV brasileira são fundamentais para nos ajudar a compreender o desenvolvimento de novas formas de tratamento dado a esse produto cultural. Por intermédio das práticas dos fãs brasileiros, novas formas de fruição passaram a constituir a experiência das audiências com os desenhos animados japoneses um pouco antes da virada do milênio. Tal cenário foi acompanhado pela popularização da Internet de banda larga no Brasil, o que nos ajuda a compreender a migração do público consumidor de animês de uma mídia mais antiga para outra. De fato, o modelo intermediário e informal de distribuição e consumo dos desenhos animados japoneses que emergiu na virada do milênio teve ancoragem no movimento dos fãs e suas práticas midiáticas no ambiente das redes digitais:

As transformações advindas do processo de globalização e desenvolvimento da comunicação eletrônica impactaram altamente os rumos dos fluxos dos conteúdos midiáticos na paisagem global. Por intermédio de certas atividades colaborativas engendradas no 
seio de comunidades de fãs espalhadas no ciberespaço, produtos midiáticos estrangeiros que não figuram no mainstream da mídia global - tal como os animês - são apropriados, re-significados e compartilhados com outros fãs no ambiente on-line. Objetivamente, nos interessa que esses conteúdos passaram a ser traduzidos, legendados e livremente distribuídos - de fã para fã - no ciberespaço, sem a mediação (e permissão) das holdings responsáveis pelo fluxo oficial desses bens no mercado mundial (URBANO, 2013, p. 57).

Essa atividade de tradução, legendagem e distribuição voluntária e gratuita ficou conhecida como fansubbing, o que etimologicamente representa a junção das palavras de língua inglesa fan e subtitle (legenda). No caso particular do Brasil, se utiliza a palavra "fansubber" para designar tanto as pessoas que realizam a atividade quanto a prática em si. A princípio, utilizando-se da tecnologia VHS, que permitiu as primeiras produções de legendas entre os fãs estadunidenses (JENKINS, 2009) e, posteriormente, lançando mão das facilidades da internet e da comunicação p2p, a atividade do fansubbing se expandiu consideravelmente e ganhou novos contornos. Atualmente, existem muitos grupos de fãs que traduzem animês para diversas línguas, sendo difícil precisar, quantitativamente, o número de grupos em atuação na rede. Versões de animês legendados em inglês, italiano, chinês, espanhol e taiwanês, dentre outras línguas, são disponibilizadas para outros fãs numa rapidez e velocidade que sugerem a atuação desses grupos em escala global (LEE, 2011; CWIEK-ROGALSKA, et. al., 2015; RONG, 2014).

Embora a prática fansubber não esteja limitada ao ambiente digital, visto que Jenkins (2009) ressalta que já existia uma movimentação de fãs que traduziam e legendavam animês e exibiam para um público restrito nos Estados Unidos desde a década de 1970, é com a popularização da internet que essa atividade se torna mais evidente, dado o barateamento de custos e facilidades proporcionadas pela comunicação mediada pelo computador entre os membros dessas comunidades: "À medida que o custo baixou, a produção de legendas se espalhou, e os clubes passaram a utilizar a Internet para coordenar suas atividades, distribuindo as séries a serem legendadas e recorrendo a uma comunidade maior de candidatos a tradutores" (LEONARD apud JENKINS, 2009, p. 221). Dado esse contexto, é perceptível que os fansubbers passaram, direta ou indiretamente, a influenciar a produção e distribuição de conteúdos televisivos em seus países de origem. 
No Brasil, é difícil precisar quando surge o primeiro grupo de fansub. Assim como ocorreu nos Estados Unidos, a prática de legendagem de animês já existia através de redes informais de amigos e conhecidos e que foi expandida com a chegada da internet. Alguns fãs acreditam que o B.A.C (Brasil Anima Club) tenha sido o primeiro grupo de fansub no país, em 1996. Além de legendar e distribuir os animês, o grupo também promovia mostras culturais desse produto em Brasília. Um ano mais tarde, o BAC passou a compor, juntamente com os grupos K-Anime, Paradoxx e Shin Seki Anime, o Projeto Anime Plus, um projeto com fins colaborativos que consistia na produção de legendas de títulos de animês de interesse entre os grupos (URBANO, 2013, p. 71). Esses grupos pioneiros buscavam a popularização do animê em território nacional e ressaltavam que o trabalho era voluntário e sem fins lucrativos. Além disso, os grupos não distribuíam animês que já haviam sido licenciados no Brasil. Nisso, atenta-se para a predominância de uma economia moral (JENKINS et al, 2014; SIGILIANO; BORGES, 2019), que norteia as atividades desses fãs, na qual todos os participantes devem seguir as premissas éticas e morais que regulam as atividades dos fansubbers historicamente desde seu surgimento.

Nos primeiros anos da década de 2000, os grupos brasileiros se reuniam em plataformas de comunicação como o IRC (Internet Relay Chat) e, mais tarde, seguindo uma tendência mundial, também passaram a manter fóruns de discussão e sites. Com a chegada das redes sociais digitais, como o Orkut, Facebook e Twitter, os grupos acompanharam essas transformações e foram incorporando essas novas ferramentas, sendo possível um acompanhamento das atualizações, postagens e curiosidades sobre os lançamentos dos episódios dos animês legendados pelos grupos. A grande variedade de gêneros e temáticas dos animês, voltadas para atingir públicos segmentados, permitiu também que os fansubs se especializassem nas convenções de gênero a ele atreladas. Assim como há grupos que dão exclusividade para projetos que contemplem animês do gênero shounen (destinado a jovens do sexo masculino), shoujo (direcionado ao publico feminino), outros se especializaram em gêneros tais como o yaoi (temática homossexual masculina) e o yuri (temática homossexual feminina), dentre outros que dificilmente encontrariam espaço dentro das grades das redes de televisão local. Mas o que prepondera é a diversidade dessas produções, permitindo 
aos fansubbers brasileiros trabalharem com projetos ligados aos seus gostos pessoais, como também concede aos fãs-consumidores o direito de escolher o que mais conveniente lhes parecer.

Naturalmente, existe uma relação direta entre os grupos de fansub e a competência ou letramento midiático (SIGILIANO; BORGES, 2019), visto que as dinâmicas estabelecidas por esses fãs demandam uma constante aprendizagem de novas linguagens, dinâmicas e sistemas a serem utilizados a fim de acompanhar tendências e estar em diálogo com o público. Basicamente, as funções que cada fansubber desempenha no decorrer do processo de produção são: 1) Raw hunter: fã que detém o arquivo do animê puro, ou seja, com a imagem e o som originais; 2) Tradutor: responsável pela tradução do texto (inglês/japonês para o português); 3) Typesetter: fã que opera na marcação de legendas, cria créditos e logotipos, placas e notas explicativas de termos; 4) Revisor: verifica possíveis erros ortográficos no texto já traduzido; 4) Timer, atua na sincronização entre legenda e áudio e; 5) Karaokê maker, responsável pelo karaokê das músicas de abertura e de encerramento dos animês. Os programas mais utilizados nessas produções são: Adobe After Effects, Aegisub, MeGUI, MKV tools.

Por fim, nos últimos anos, a atividade dos fansubbers brasileiros na internet brasileira e seu modelo intermediário e informal de distribuição dos animês que, teve bastante êxito até pouco tempo atrás, vem tendo seu status ameaçado, devido ao surgimento de novos atores e forças oriundas do mercado oficial de distribuição desse produto. Novos modelos de distribuição e consumo de animês, surgidos a partir da emergência de plataformas de streaming licenciadas, vêm promovendo mudanças significativas nas formas de se ter acesso a esse produto cultural no Brasil.

\section{O novo modelo de distribuição e consumo de animês: os ser- viços de streaming no Brasil}

A plataforma americana de streaming de filmes e séries Netflix tem se consolidado como uma das principais produtoras e distribuidoras de conteúdo audiovisual do mercado global (CASTELLANO; MEIMARIDIS, 2016). Embora a Netflix tenha iniciado as suas atividades como um ser- 
viço de aluguel e vendas de fitas e DVDs nos Estados Unidos em 1997, foi somente em 2007 que a empresa passou a fornecer conteúdo on demand via streaming. Em 2010, a Netflix já estava presente em seu formato de aplicativo para smartphones e tablets e dava os primeiros passos para a internacionalização de seus serviços, além de ter fechado acordo com grandes produtoras e distribuidoras como a Sony, Warner e Disney (ROSSINI; RENNER, 2015). No ano seguinte, seus serviços alcançaram os países da América Latina, dentre os quais o Brasil, trazendo em seu catálogo uma gama de filmes, séries, desenhos animados estrangeiros e também algumas produções nacionais. Dois anos mais tarde, a empresa passou a investir na criação de conteúdo original exclusivo, através da série House of Cards (2013 - 2018) e, com isso, deixou de operar apenas como uma distribuidora, firmando-se no mercado global como uma forte produtora de conteúdo, reconhecida pela qualidade de seu conteúdo original (CASTELLANO; MEIMARIDIS, 2016).

Nos últimos anos, a Netflix tem atuado de forma a diversificar as nacionalidades das produções disponíveis em seu catálogo e, com isso, encontramos conteúdo licenciado e exclusivo oriundo de países como Japão, Coreia do Sul e Índia. Esse movimento ilustra a importância adquirida pelo contrafluxo das produções televisivas do Leste Asiático, em um contexto no qual a indústria midiática se apresenta cada vez mais de forma multipolar. Assim, observa-se a presença de uma centena de títulos de animês, separados em uma categoria específica dedicada a esse formato, na qual constam desenhos animados japoneses produzidos e coproduzidos pela Netflix, dentre os quais destacam-se a produção original Aggretsuko (2018 - presente), série animada realizada em parceria com a empresa Sanrio, Carole and Tuesday (2019), coproduzida com a TV Fuji e o remake do fenômeno Cavaleiros do Zodíaco (2019 - presente), coproduzido ao lado da Toei Animation. A Netflix também tem licenciado uma série de títulos já conhecidos do grande público, como Full Metal Alchemist (2011), Naruto (2002 - 2007) e Samurai X(1996 - 1998).

Já o Crunchyroll é uma empresa norte-americana que deu início às suas atividades em 2006 como um site de streaming e upload de vídeo, com fins lucrativos, que se especializou em hospedar conteúdo de vídeo asiático oriental, como animês, mangás, dramas de TV e programas musicais, muitas vezes, ilegalmente. De acordo com Mello e Vieira (2019), o Crunchyroll chegava até mesmo a utilizar as legendas feitas 
por fansubbers, mesmo sem um acordo prévio com os grupos, além de também não comprarem os direitos autorais dos animês que distribuiam. Com o passar do tempo, no entanto, a companhia firmou acordos de distribuição com produtoras e distribuidoras japonesas (como a Gonzo, TV Tokyo e Toei Animation) e, com isso, ampliou a quantidade de títulos disponíveis em seu site. Em 2009, a plataforma de streaming assumiu o compromisso de remover de seu site todos os materiais que infringiam direitos autorais e disponibilizar para o consumo somente conteúdos sobre os quais possuía os direitos para a distribuição.

Em 2017, o Crunchyroll ultrapassava a marca de 800 animês licenciados para a distribuição nos Estados Unidos e com 600 títulos disponíveis no Brasil (MELLO; VIEIRA, 2019), prestando um importante serviço à comunidade de fãs, dada a quantidade de títulos sendo transmitidos, com alta qualidade de vídeo, simultaneamente a sua transmissão original no Japão e de maneira oficial, o que até pouco tempo atrás não era possível. Sem dúvida, com sua vasta quantidade de conteúdo, o Crunchyroll expressa a possibilidade de acompanhar animês de diversas redes de televisão japonesas com uma diferença de tempo diminuta, além de permitir aos consumidores acompanhar alguns animês sem a necessidade de recorrer a downloads.

De modo geral, as legendas disponibilizadas por serviços de streaming licenciados são estruturalmente diferentes daquelas produzidas pelos fansubbers, visto que as amadoras são caracterizadas por uma estética do excesso, nas quais se apresentam uma série de características com as quais os fãs se habituaram e apreciam, como a adoção de notas explicativas ao longo dos episódios e "[...] efeitos nos karaokês, logos animadas: diversas intervenções de natureza escrita e visual [...] mas que, sobretudo, eram vistas como sinal de qualidade para alguns indivíduos mais aficcionados" (URBANO, 2013, p. 137). Dessa forma, ainda são os fansubbers que, juntos, conseguem proporcionar ao consumidor um acervo de animês mais próximo ao exibido no Japão, além de apresentarem um trabalho de tradução e legendagem dotado de características que são caras à essa comunidade de fãs.

Dado todo o exposto, compreendemos que os modelos de distribuição e consumo de animês em voga atualmente no Brasil coexistem e sobrevivem em uma dinâmica constante de retroalimentação. Embora o fluxo dos animês nas redes de televisão brasileiras tenha realmente 
decaído nos últimos anos, tanto as emissoras públicas quanto as privadas continuam a exibir desenhos animados japoneses (sobretudo aqueles considerados clássicos do gênero) em suas grades televisivas. Não obstante, os fansubbers brasileiros continuam a ter um papel fundamental no desenvolvimento de uma base de fruição e consumo dos animês, através das quais o mercado de streaming que hoje atua dentro do país vem amplamente se beneficiando. Afinal, como o próprio CEO da Netflix, Reed Hastings, salientou: a pirataria é um dos indicadores de conteúdo a ser utilizado na plataforma, a fim de perceber as demandas e suprir as necessidades dos espectadores (CAPANEMA, 2013). Mesmo que os conglomerados de mídia tentem frear a "distribuição alternativa" de produtos midiáticos, tal como ocorreu recentemente com o próprio Crunchyroll (YUGE, 2019), e ainda sejam precisas mais investigações acerca das disputas e tensões existentes no diálogo entre os fãs brasileiros e as plataformas de streaming oficiais, é possível sugerir que essa multiplicidade de alternativas de distribuição e de consumo de animês no Brasil contribua exponencialmente para a contínua expansão e popularização da cultura pop japonesa no Brasil.

\section{Considerações Finais}

Diante da multipolaridade do mundo, na qual conteúdos televisivos de países não ocidentais têm se apresentado como uma alternativa aos programas oriundos exclusivamente do eixo Estados Unidos e, em menor escala, da Europa Ocidental, discutimos neste artigo sobre o fluxo dos desenhos animados japoneses no Brasil. Para tanto, exploramos a trajetória dos animês em nosso país através de uma perspectiva sócio-histórica, chegando em três variáveis dos modos de distribuição e consumo desse dado produto cultural em voga em nosso país. A primeira delas, o modelo clássico licenciado, é representado pela mídia televisiva local e emissoras abertas e a cabo que ainda veiculam esse tipo de conteúdo em suas grades. Já a segunda variável dá conta de ilustrar o surgimento de um modelo intermediário não licenciado, ancorado no ambiente digital e impulsionado pelo movimento dos fansubbers brasileiros. Por fim, a terceira variável aborda o modelo vigente licenciado, representado pela emergência das plataformas de streaming, como a 
Netflix e o Crunchyroll.

Dito isso, defendemos que a recente popularização das plataformas de streaming oficiais de animês enquanto um novo modelo de distribuição desse produto cultural se apresenta como uma alternativa promissora no consumo dos desenhos animados japoneses no Brasil, que outrora dependiam exclusivamente das emissoras locais ou do trabalho dos fãs para encontrar uma alta diversidade de títulos dublados e/ou legendados. Nessa direção, os consumidores brasileiros hoje se encontram em um cenário em que as possibilidades de fruição de animês se tornaram mais amplas. Enquanto os serviços de streaming são pagos ou possuem versões pagas para a obtenção de uma qualidade superior de imagem ou remoção de propagandas, os fansubs entregam um material gratuito e dotado de um capital subcultural em contraponto ao modelo oferecido pelo mercado oficial. Além disso, as redes de televisão (abertas e fechadas), apesar de todo o exposto, continuam ocupando um papel preponderante na difusão da cultura animê junto aos públicos eventuais no país.

Acreditamos, por fim, que a coexistência desses modelos de distribuição licenciados e não licenciados, encabeçado pela indústria dos animês, as emissoras locais e seus fãs, promove uma diversificação dos meios de acesso aos desenhos animados japoneses e, acima de tudo isso, contribui para impulsionar a difusão e expansão da cultura pop japonesa no Brasil. 


\section{REFERÊNCIAS}

CAPANEMA, Rafael. Pirataria de filmes é termômetro para formar catálogo, diz executivo-chefe do Netflix. Folha de S. Paulo, São Paulo, 30/01/2013. Disponível em: <https://www1.folha.uol.com. br/tec/2013/01/1220698-pirataria-de-filmes-e-termometro-para-formar-catalogo-diz-executivo-chefe-do-netflix.shtml . Acesso em: 08 Fev. 2020.

CASTELLANO, Mayka; MEIMARIDIS, Melina. Netflix, discursos de distinção e os novos modelos de produção televisiva. Contemporânea | Comunicação e Cultura, UFBA, Salvador, n. 02, 2016, p. 193-209. Disponível em: <https://portalseer.ufba.br/index.php/contemporaneaposcom/article/ view/16398>. Acesso em 8 fev. 2020.

ĆWIEK-ROGALSKA, Karolina; HOŁY-ŁUCZAJ, Magdalena; ŁUCZAJ, Kamil. Fansubbers. The case of the Czech Republic and Poland. Journal of Comparative Research in Anthropology and Sociology, UNIBUC, Bucareste, n. 2, 2014, p. 175-198.

CURRAN, James; PARK, Myung-Jin. De-westernizing Media Studies. New York: Routledge, 2000.

HOLZBACH, Ariane. Para pequenos grandes espectadores: a produção televisiva brasileira direcionada a crianças pequenas a partir do caso da Galinha Pintadinha. E-Compós, COMPÓS, Brasilia, n. 2, 2018. Disponível em: <https://www.e-compos.org.br/e-compos/article/view/1390/1851>. Acesso em 8 fev. 2020.

IWABUCHI, Koichi. "How "Japanese" is Pokémon?". In: TOBIN, Joseph (Org.) Pikachu's Global Adventure: The Rise and Fall of Pokémon. Durham: Duke University Press, 2004, p. 53-59.

Recentering Globalization: Popular Culture and Japanese Transnationalism. London: Duke University Press, 2002.

JENKINS, Henry. Cultura da Convergência. São Paulo: Aleph, 2009.

JENKINS, Henry; GREEN, Joshua; FORD, Sam. Cultura da Conexão - Criando Valor e Significado por Meio da Mídia Propagável. São Paulo: Aleph, 2014.

LEE, Hye-Kyung. Participatory media fandom: A case study of anime fansubbing. Media, Culture \& Society, Califórnia, n. 33, 2011, p. 1131-1147.

MACHADO, Igor José R. (Org.). Japonesidades multiplicadas: Novos estudos sobre a presença japonesa no Brasil. São Carlos: EdUFSCar, 2011.

MATTOS, Sérgio. História da televisão brasileira - Uma visão econômica, social e política. Petrópolis: Ed. Vozes, 2002.

MELLO, Anna; VIEIRA, Eloy. Fansubbing e streaming no Brasil: Um panorama do consumo de animes legendados por fã. Anais do XX Congresso de Ciências da Comunicação na Região Sul, Porto Alegre, Brasil, 2019. Disponível em: <http://portalintercom.org.br/anais/sul2019/resumos/R65-16421.pdf>. Acesso em 8 fev. 2020.

MITTELL, Jason. The great Saturday morning exile: Scheduling cartoons on television's periphery in the 1960s. STABILE, Carol; HARRISON, Mark (orgs.). Prime Time Animation: Television Animation and American Culture. New York, Routledge, 2003, p. 33-54. 
MONTE, Sandra. A presença do animê na TV brasileira. São Paulo: Ed. Laços, 2010.

NAGADO, Alexandre. Almanaque da Cultura Pop Japonesa. Via Lettera, 2007.

PEREIRA, Paulo Gustavo. Almanaque dos seriados. São Paulo: Ediouro, 2008.

RONG, Zongxiao. Hybridity within peer production: The power negotiation of Chinese fansub groups. Dissertation (MSc in Media, Communication and Development) - Department of Media and Communications, London School of Economics and Political Science, 2014.

ROSSINI, Miriam; RENNER, Aline Gabrielle. Nova cultura visual? Netflix e a mudança no processo de produção, distribuição e consumo de audiovisual. Anais do XXXVIII Congresso Brasileiro de Ciências da Comunicação, Rio de Janeiro, Brasil, 2015. Disponível em: <https://lume.ufrgs.br/bitstream/ handle/10183/129873/000973714.pdf?sequence=1\&isAllowed=y>. Acesso em 8 fev. 2020.

SATO, Cristiane A. Japop - o poder da cultura pop japonesa. São Paulo: NSP- Hakkosha, 2007.

SIGILIANO, Daiana; BORGES, Gabriela. Fansubbing: o diálogo entre a competência midiática e a produção dos fãs de ficção seriada. Revista ANIMUS, UFSM, Santa Maria, n. 38, 2019, p. 249-268. Disponível em: <https://periodicos.ufsm.br/animus/article/view/36067/pdf>. Acesso em: 8 fev. 2020.

THUSSU, Daya. K. Mapping global media flow and contra-flow. In: THUSSU, D. K (ed.). Media on the Move: Global flow and contra-flow. London \& New York: Routledge, 2007, p. 11-32.

URBANO, Krystal. Legendar e distribuir: o fandom de animês e as políticas de mediação fansubber nas redes digitais. Dissertação (Mestrado) em Comunicação. Niterói: Instituto de Arte e Comunicação Social, Universidade Federal Fluminense, 2013.

WANG, Georgette (ed.). De-Westernizing Communication Research: Altering Questions and Changing Frameworks. London \& New York: Routledge, 2011.

YUGE, Claudio. Polêmica: sites de animê brigam com Crunchyroll por combate à pirataria. Tecmundo, Curitiba, 06/02/2019. Disponível em: <https://www.tecmundo.com.br/internet/138502-polemica-sites-acusam-crunchyroll-acao-ilegal-combate-pirataria.htm>. Acesso em: 02 Set, 2020.

Data do recebimento: 09 fevereiro 2020

Data da aprovação: 07 outubro 2020 


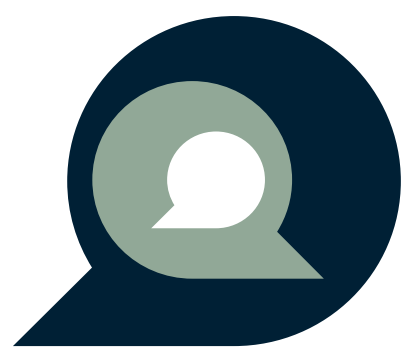

